\title{
Stylistics Analysis in Advertising Discourse: A Case of the Dangote Cement Advertisement in Bamenda- Cameroon
}

\author{
Seino Evangeline Agwa Fomukong \\ The University of Bamenda, Cameroon \\ E-mail: seinoeva2014@yahoo.com
}

Doi:10.7575/aiac.alls.v.7n.6p.105

Received: 01/08/2016

URL: http://dx.doi.org/10.7575/aiac.alls.v.7n.6p.105

Accepted: 16/10/2016

\begin{abstract}
There are many purposes for using language which determine how the writer or speaker chooses words, syntactic expressions and figurative language. This is as a result of the fact that language has a very powerful effect over people, their actions and thoughts. This is seen in the use of language in various discourse types which include advertisements. The powerful influence language has on people therefore makes encoders to be choosy in the use of language, especially in advertisement because they have to persuade the readers. Consequently they make the language of advertisements positive and emphasize on the superiority of their products. This study discusses the advertisement of Dangote Cement on billboards in Bamenda, North West Region, Cameroon, analysing what is communicated, how it is communicated and the interpretation. The analysis used as tools the Textual Conceptual Functions as given by Jeffries (2016), uncovering ideologies and social meanings expressed in Dangote Cement advertisement using the following apparatus: prioritisation, implying and assumption, listing, naming and description. The study has emphasized the structural analysis and the role of context to reveal functions and underlying meanings of the text. It also concludes that the advertisers use different stylistic devices that carry positivity, and a common ground that makes the readers identify with the advertisements, urging them go for the Dangote Cement.
\end{abstract}

Keywords: stylistics, language, context, advertisements, ideologies, Dangote

\section{Introduction}

There are many purposes for using language which determine how the writer or speaker chooses words, syntactic expressions and figurative language. This is as a result of the fact that language has a very powerful effect over people, their actions and thoughts. Because language is not static or rigid, it is used in a dynamic and volatile way as the different situations of use arise. This is seen in the use of language in various discourse types which include advertisements, newspapers, sermons, lectures. The different discourse types go along with different purposes. One of the major purposes for using language therefore, is to persuade the audience. In using persuasive language the speaker or writer convinces the listener or reader to carry out an action or buy an idea. This is true in the language of advertisement, where the encoder of the advertisement makes choices of language that will manipulate the minds of the readers or consumers, urging them to buy a product. To achieve this effect therefore the advertisers take into consideration the conative and emotive power of the lexical and syntactic structures they use. They also consider the idea they want to communicate, making way for the connotational meanings of the text.

The powerful influence language has on people makes encoders to be choosy in the use of language, especially in advertisement because they have to persuade the readers. Consequently they make the language of advertisements positive and emphasize on the superiority of their products. They use techniques that are deviant and catchy. Crystal (2003, pp.388) argues that these advertisements stand out stylistically on several counts. He explains that they are lexically vivid, concrete, positive and unreserved and, grammatically they are typically conversational and elliptical, and they also have highly figurative expressions, deviant graphology and strong effects. Linghong (2006) is in line with this view by confirming that in order to secure a number of readers and to compete with many other similar advertising messages, advertisers try to make their advertisements as effective as possible. They use various linguistic devices to catch attention, arouse desire, induce action and contribute towards satisfaction. Advertising texts are therefore distinctive, with an unusual and indirect language.

Considering that in advertising, participants only engage in the discourse passively, the encoders make use of concepts that build relationships and vocabulary which will make the readers desire to go for the product. In building on the interpersonal relationship between advertiser and consumer, they try to establish truth and goodwill in their advertisements (Maria Stanatelou, 2015). The advertisers make efforts to engage the reader by providing models for consumer needs, values, taste, and behaviour. According to Fairclough (1989, pp 207), the positions for consumers are built by presupposing that consumers need to be or aspire to have certain beliefs, aspirations and financial standards, adopting the cultural view of the language of advertisement. The fact that an advertisement deeply embeds into 
consumers' minds has to carry an aspect of the culture of the target audience. Myers in Culpeper et al. (2009, pp. 456) comments that 'most adverts we see and hear in the course of a day are trying to do something rather more complicated; they have to place that brand in systems of linguistics and visual symbols, place the advert where the right people see it, and engage those people in the process of interpreting the advert.' The right people are those who will understand and be able to interpret the advert. For the people to engage in the process of interpreting, the advert has a tie with the culture of the people, that is, the things they are engaged in, daily. This view is expressed by Adams et al. (2014) saying an advertiser's intention is to give meaning to a product by developing associations in the mind of the reader or listener and persuading them to buy it. They go on to emphasis that these associations are cultural in the sense that any member of the culture for which the advertisement is produced will find them easy to recognize. The interpretation of these cultural aspects warrants the contextual elements to come into play for the interpretation of the advert.

The features in advertising language are therefore attractive and contextual. This is revealed in the research carried out by some researchers in the field of advertisements, focusing on linguistic issues. This is the view of Li (2009) in the analysis of Atkins Chocolate Chip Granola Bar. In this article Li does a textual and contextual analysis of the chocolate advertisement, examining graphological, lexical, syntactic, grammatical and semantic style markers. Li concludes that the advertisement uses well-organised language, eye-catching pictures and affirmative adjectives to describe the product, which helps the producer to better communicate with consumers. Jafari and Mahadi (2014) look at the fundamental and main characteristics of advertising language, examining major concepts like advertising, persuasion and communication. They conclude that advertising language is a persuasive language linked to culture and has simple statements, short indirect sentences and sentence fragments that have distinctive value of emphasis and association. Duboviciene and Skorupa (2014) in their article describe the use and purpose of linguistic devices in print advertisement. In the advertisement slogan they focus on figurative language and sound techniques used at the phonological, lexical, syntactic and semantic levels. They conclude that advertising slogans are short catchy phrases related to specific brands which define, present and help customers remember the key concepts of a brand or advertising campaign. They sum up the analysis revealing that $40 \%$ of the sampled slogans contain figurative language, $32 \%$ use sound techniques and $28 \%$ rhetorical devices, and the most used sound technique is alliteration, while the most used rhetorical device is repetition. The analysis of advertisements therefore focus on the persuasive nature of textual and contextual elements in advertisements.

It is in this light that this study is going to discuss the advertisement of Dangote Cement on billboards in Bamenda, North West Region, Cameroon, analysing what is communicated, how it is communicated and the interpretation. It therefore delves into the ideologies behind the advertisement, the stylistic devices used and the process of interpretation which links the advertiser's intention to change the mental state of the readers and the readers' way of inferring this intention. The study takes into account not only the internal text structure but also what people or readers know about the world in which the text is embedded. The analytic apparatus of stylistics are used to analyse the advertisement of Dangnote Cement on billboards in Bamenda. The Dangote Cement is owned by Aliko Dangote, a Nigerian billionaire, who owns the Dangote Group which has interests in commodities. The company operates in Nigeria and some other African countries, Cameroon inclusive. Dangote is Africa's richest man, founded and chairs Dangote Cement, the continent's largest cement producer (www.forbe.com/profile/aliko-dangote/). This cement is distributed in Cameroon generally and in Bamenda particularly. The advertisement is found on billboards and on doors and walls of business houses that participate in the distribution of the cement. Dangote Cement has become a household name for constructing companies and individuals building houses in Bamenda, North West Region of Cameroon.

\section{Background to the Study}

Stylistics is the linguistic study of style in language. Its objective is to delve into the manner in which a text projects meaning and how this meaning is construed by readers. These texts can be literary or non-literary. Simpson (2004, pp. 2) describes 'stylistics as a method of textual interpretation in which primacy of place is assigned to language.' According to Simpson language is important to the stylistician because the various forms, patterns and levels that constitute linguistic structure are important in the function of the text. Simpson goes on to argue that while linguistic features do not themselves constitute a text's meaning, an account of linguistic features nonetheless serves to ground a stylistic interpretation and helps explain why for the analyst, certain types of meaning are possible

Short in Culpeper et al. (2009,pp 464) states that stylistics is mainly concerned with trying to explain how, when we read texts particularly (but not exclusively literary texts), we get from the words on the page to an understanding of the text, and how the words on the page affect us in the way they do. Stylisticians do this by analysing the language of texts and relating that analysis to what they know about how readers interaction with texts. This means that the focus of stylistics is language, be it literary or non-literary.

Stylistics, as a sub-discipline of linguistics started in the second half of the twentieth century with the most influential actor being Roman Jakobson. Stylistics can be seen as emanating from the discussions within literary criticism in the early twentieth century. This move explains why stylistics started with a focus on literary texts. With the developments in stylistics, later linguists saw that since stylistics looks at the language of texts, their meaning and the effect on readers, then nonliterary texts can also be analysed stylistically. Simpson (2004, pp. 2) argues that 'the creativity and innovation in language use should not be seen as exclusive preserve of literary writing.' He further explains that many forms of discourse -advertising, journalism, popular music and even casual conversation- often display a high degree of stylistic dexterity, such that it would be wrong to view dexterity in language use as exclusive to canonical literature. 
Jeffries et al. (2010, pp. 2) support this view when they state that 'stylistics has tended to concentrate on the analysis of literary texts, though there is in fact no reason why this should necessarily be the case.' The stylistic features, they go on to discuss, are not exclusive to one genre but are techniques that can be applied equally to non-literary texts.

Stylistics has also moved from what Simpson (2004, pp. 3) considers, 'the grammarian who spends rather too much time on such trivial pursuits as counting the nouns and verbs in a literary text' to what Jeffries et al. (2010, pp. 2) consider 'not simply concerned with identifying formal features of style in language' but 'how the texts that surround us may subtly and sometimes even deliberately influence our political, social and even consumerist outlooks' (pp, 8). This modern view of stylistic analysis explores the creativity in the use of language and makes relevant all aspects of an encoder's craft which are the language system, textual meaning, the interpretation, and the effect.

Considering all these aspects, stylistic analysis has moved to a more radical method focusing on the hidden ideologies of texts. According to this view, critical stylisticians analyse texts uncovering ideologies through grammatical features in the texts. This links to critical discourse analysis which has a methodology that delves into the analysis of institutional discourse, especially language of politics, mass media and advertising, and as Yiebo (2011, pp.107) explains, to disclose the ways societal structures and processes are encoded in the discourse practices. This relates to Critical Discourse Analysis in that as Dijk (1995) explains, 'Critical Discourse Analysis has become the general label for a special approach to the study of text and talk, emerging from critical linguistics, critical semiotics and in general from a socio-political conscious and oppositional way of investigating language, discourse and communication.' For this to be effective the issue of contextualization has to be considered for success in interpretation. This means that the analyses will include the knowledge of elements outside the text and how they contribute to create a cultural identity.

Stylistics is interested in language as a function of texts in context, and it acknowledges that utterances (literary or otherwise) are produced in a time, a place and in a cultural and cognitive context. The 'extra-linguistic' parametres are tied up with the way a text means. Therefore the more complete and context-sensitive the description of language, then the fuller the stylistic analysis that accrues (Simpson 2004, pp.3).

According to Fairclough (1992) as quoted by Stamatelou (2015, pp.15) 'language use reflects culture and it is impossible to disassociate the two in any real sense - the way a culture sees the world is reflected in its language.' In Halliday's (1978, pp. 89) view, language is controlled by the social structure, and the social structure is maintained and transmitted through language.' Halliday (1978,pp 89) goes a little further to argue that language plays a central role both as a determiner, insinuating that the language system is inseparable from the social context. This makes the context-dependent elements in the interpretation of texts imperative, meaning that in interpretation, what is said, determined by linguistic rule, and what is implicated determined by social and other contextual factors, are considered. This brings in implicature which refers to what is suggested in an utterance even though not overtly expressed and through this, brings to the surface hidden ideologies in a text, which are about meaning in speech situations, insinuating that an utterance is said with some illocutional goal in mind, making pragmatic meaning important since it describes the forces acting in the interpretation of a given utterance, meaning it is context-dependent. The decoder puts together the utterance and other contextual factors to get the encoder's intention, which is the implied meaning. With an intention in mind the reader or listener has to infer into the utterance together with contextual features to get the writers intended meaning bringing to play the cultural elements the reader needs, to be conversant with, so as to decode the intended meaning. The speaker's intention is the implicature which is deducible from the input and the context together.

\section{Theoretical Framework}

\subsection{Textual Conceptual Functions}

The theory used for this study is the Textual Conceptual Functions (TCFs) of Lesley Jeffries (2016). Stylistic judgments are based on evidence from texts and use linguistic models to account for this analysis. This takes stylistics to a critical perspective which functions in the text. Jeffries gives a description of the language of a text linked to a set of interpretations. This is explained in the Textual Conceptual Functions (Jeffries 2016) which has three type of meanings, which are the linguistic, the ideational and the interpersonal. The linguistic meaning as explained in Jeffries (2016) includes the de-contextual, structural and semantic meanings that examine the levels of language which are phonology/graphology, morphology lexis, syntax, discourse. The linguistic meaning is the core meaning, fundamental to all language use. The ideational (textual-conceptual meaning) is the co-textual effects of linguistic choices made by language users. Here, the analyst takes into consideration the linguistic environment in which a word is used within a text. At this level gives a set of textual meanings that can be used in analysing the text, exposing the different ways in which texts represent the world. The interpersonal is the pragmatic meaning that focuses on the contextual intention of linguistic uses on others. At this level the analyses is on the way interlocutors interact and the ways the producers seek to achieve their intentions by using language in speech acts, and implicatures. These three type of meanings are portrayed diagrammatical on figure 1 , below. 


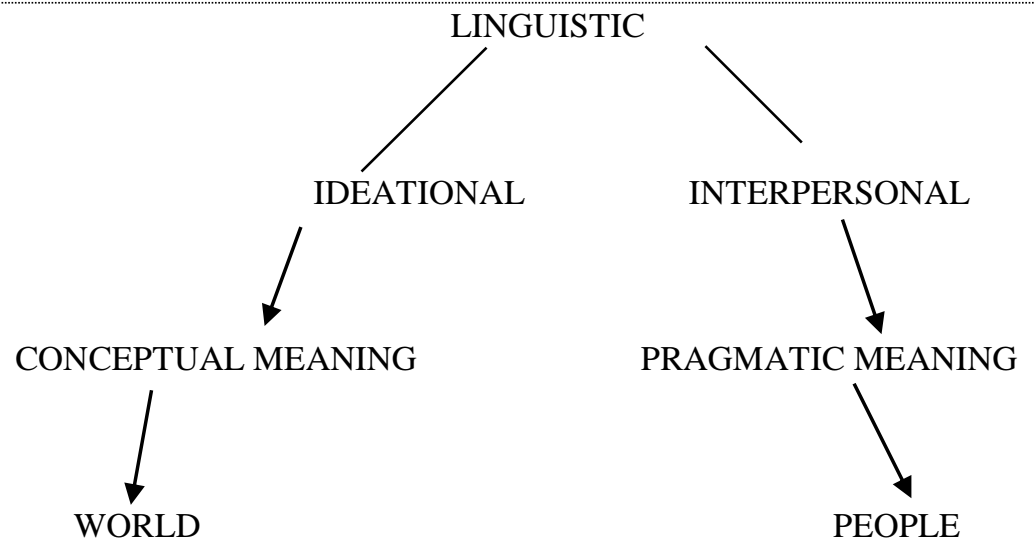

Figure 1. Three type of meanings by Jeffries (2016)

With the above in mind, this study is going to analyse the advertisement of the Dangote Cement, found on billboards in Bamenda, North West Region, Cameroon. The analysis will use as tools the Textual Conceptual Functions as given by Jeffries, (2016) and explained by team@languageinconflict.org. It will focus on what is communicated and how it is communicated and how it is interpreted. In analysing the linguistic structures and discourse strategies in the light of their interactional (even though passive) and wider social contexts, this study will uncover ideologies and social meanings expressed in Dangote Cement advertisement using the following apparatus: prioritisation, implying and assumption, listing, naming and description.

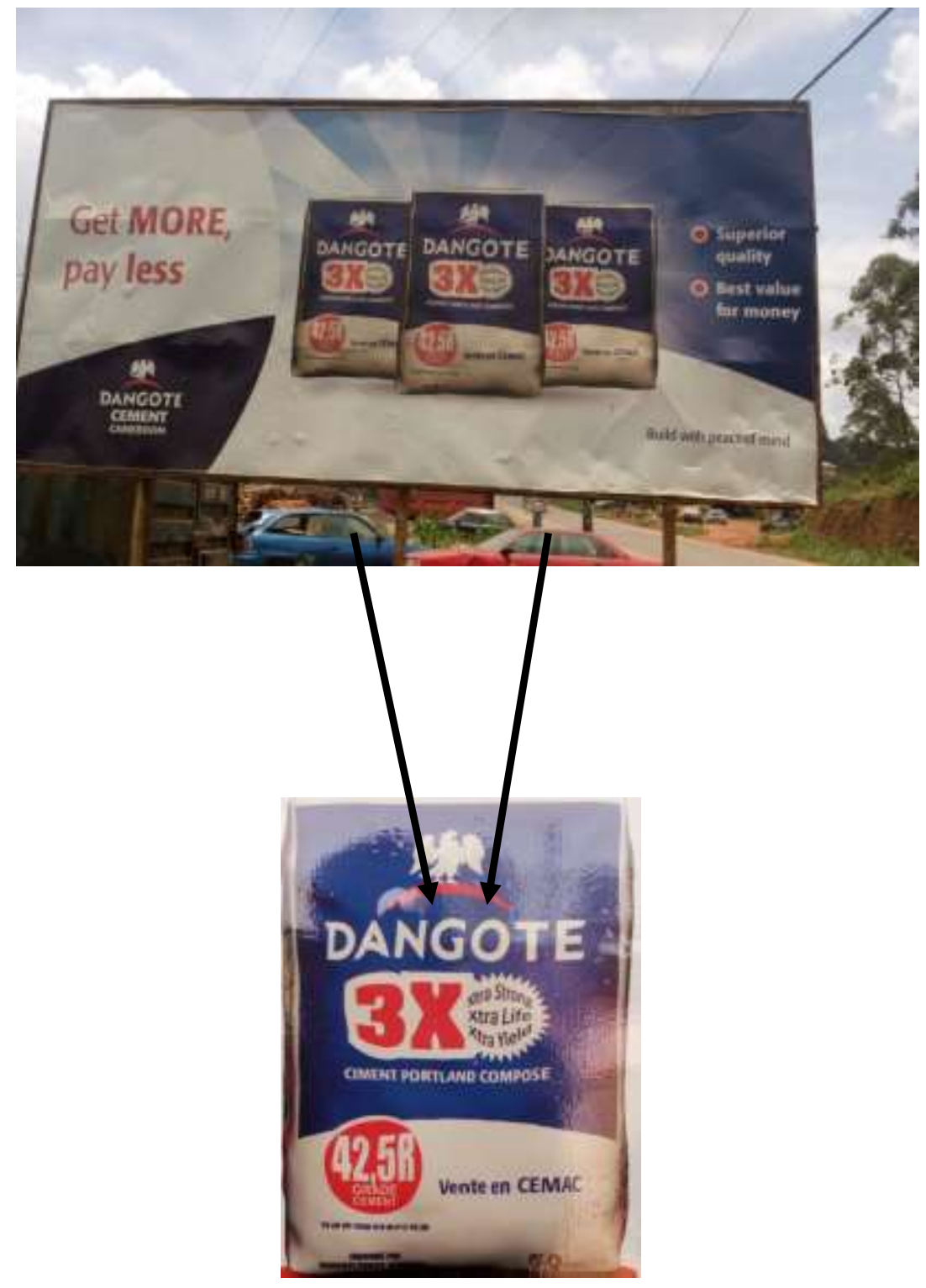

Figure 2. Dangote Cement billboard in Bamenda, North West Region, Cameroon. 


\section{Results and Discussion}

In this section the analysis of the Dangote Cement advertisement will be done using the following elements as discussed by Jeffries in the textual conception functions. These are prioritisation, naming and describing, implying and assuming, listing, naming and description.

\subsection{Prioritising}

As argued by team@languageinconflict.org, prioritising is when in a sentence 'we choose (consciously or not) what information to emphasize.' Prioritising therefore draws attention to a particular piece of information, focusing on the information structure of the sentence in three main ways. These are placing new and important information at the end of the sentence, the final clause elements of the passive sentence and placing less important information in the subordinate clause. This study looks at prioritising from the point of view of graphology that is, choosing to emphasize some information through the use of capitals and bolds. As Crystal (2003, pp. 388) says, language of advertisement has deviant graphology.

In the Dangote Cement advertisement, '3X, MORE and less, and DANGOTE, xtra Strong, xtra Life, xtra Yield', are prioritised. These items are highlighted, that is, they are written in bold and in red which is 'assertive and domineering. $3 \mathrm{X}$ is highlighted in bold and in red; MORE is in bold and capitals, 'less' is highlighted in bold and 'DANGOTE' is in capitals. 3X, draws attention to the name of the product and the strength of the product 'xtra Strong, xtra Life and xtra Yield', emphasizing validity. 'MORE' is bold and in capitals while 'less' is bold but in the lower case. This is so because the intentions of the advertisers is to sell the idea of cheapness and strength. The highlighting of 'DANGOTE' carries a more contextual interpretation through implying. Also the use of capitals in the middle of a phrase is deviant in a syntactic structure and calls attention. This is used in 'xtra Strong, xtra Life and xtra Yield.' These aspects of prioritising carry strong effects in the language used, confirming validity, predictably and desirability of the Dangote Cement.

\subsection{Listing}

Another textual function discussed by team@languageinconflict.org is listing. Here, they differentiate exemplification from enumeration. When listing they explain that exemplification provides an instance or several instances of a certain phenomenon and enumerating provides a list of instances. These items are sometimes being introduced by connective phrases such as 'for example' and 'for instance' to distinguish exemplification from enumeration. Enumerating provides a complete list. In the advertisement of 'Dangote Cement' there is listing by enumeration. The $3 \mathrm{X}$ leads to 'xtra Strong, xtra Life, xtra Yield' and probably because of time and space, and intentional call for attention, the advertisers do not use a form of syntactic introduction but give a stylistic representation of $3 \mathrm{X}$. The use of $3 \mathrm{X}$ is more economic, stylistic and catchy than when written in words as in 'three extras' for example. The listing follows the three part list or triad which is powerful, attention - grabbing and stylistic to readers. The advertisers make use of the noun phrase in the triad.

The rule of three is used within marketing and advertising and the most common uses is related to Marketing theory and slogan creation. As elaborated by rule-of-three.co.uk/2011/7/2 what-is-the-rule-of-three-copywriting, in Marketing Theory, American advertising pioneer, E.St Elmo Lewis laid-out his three chief principles which he felt were crucial for effective advertising. He says

The mission of an advertisement is to attract a reader, so that he will look at the advertisement and start to read it; then to interest him, so that he will continue to read it; then to convince him, so that when he has read it he will believe it. If an advertisement contains these three qualities of success, it is a successful advertisement.

This is what is happening in the Dangote Cement advertisement. The triad in Dangote Cement stands out in a captivating manner and remains in the mind of the reader. The attitude of the advertiser here is to cause desirability in the consumer through practical, moral or aesthetic judgment. The three is expressed even on the number of three bags of cement on the advert. The combination of these three elements 'strong, life and yield' justify a sense of completeness because they exhibit the elements needed for the strength of cement. This completeness can be seen in the description of cement properties. According to http://civiltoday.com/civil-engineering-materials/cement/45-properties-of-good-cement (2015), although desirable, cement properties may vary depending on the type of construction. Generally a good cement possesses the following properties: it provides strength to masonry, stiffens or hardens early, possesses good plasticity, it is an excellent building material, easily workable and good moisture-resistant. The use of 'strong, life and yield' convey a sense of completeness because the properties of a good cement is made up of these qualities. 'Strong' is found in the property that it provides strength and stiffens easily, 'life' is seen in plasticity and excellent building material, and 'yield' is found in easily workable and good moisture-resistant.

\subsection{Naming and Describing}

Naming and describing looks at the ways writers refer to particular referents which can be things or people in the world around them, or more abstract concepts (team@languageinconflict). These choices are very revealing because a particular name or description given to a referent portrays the writer's view of the world and leads the reader into inferring the writer's point of view concerning that object or concept. This insinuates that naming has a powerful effect and so it is done with so much consideration. 
The name of the product being advertised is Dangote Cement. 'Dangote' is the owner of the company that produces the cement. He is a prominent businessman in Nigeria and found amongst the top business people in world status. He is a billionaire, the richest man in Africa (www.forbe.com/profile/aliko-dangote). The use of 'Dangote' attracts consumers to the cement because they feel attached to him. Using his name carries an ideological status of power and dominance over his consumers. Another description is $3 \mathrm{X}$ that leads to a listing of three qualities of the cement, is used stylistically and describes the qualities that follow 'xtra Strong, xtra Life xtra Yield. The X stands for 'extra' which is instead spelt 'xtra' to intentionally draw the attention of the readers. The morpheme (phoneme) 'ex' in extra is pronounced /eks/ and ' $\mathrm{X}$ ' is pronounced /eks/. The deviant spelling of 'extra' that is represented by ' $\mathrm{X}$ ' in $3 \mathrm{X}$ is a stylish way of making the advertisement interesting and pulling the consumers' attention.

In describing the product, the advertisers make use of ellipsis. Ellipsis refers to resources for omitting a clause, or some part of a clause or group, in contexts where it can be assumed. It is a cohesive device which serves the brevity principle, thus in advertising it saves space and money and avoids insignificant features by focusing only on the part of the message that draws attention. The ellipted elements are corresponding to, and recoverable from the text. Where these fragments are used, they are more conversational and relay information quickly. The call to action in these fragments is more like a direct order instead of a suggestion and has positive adjectives that attract readers. Two sentence fragments used in the advertisement are 'best value for money' and 'superior quality.' They are noun phrases that form part of the predicate without the verb. The complete sentences can read thus: Buying Dangote Cement is the best value for money' and 'Dangote Cement has a superior quality.' In the case of the Dangote Cement, the subject complements are noun phrases with pre-modifiers that give vivid descriptions of the subject. This is found in the phrases 'superior quality' and 'Best value for money.' The Noun Phrase, 'superior quality' is composed of a pre-modifier 'superior' and a noun 'quality.' The Noun Phrase, 'best value for money' is made up of Noun Phrase 'best value'- 'best' which is an adjective and 'value' which is a noun; and Prepositional Phrase 'for money'- preposition 'for' and noun 'money'. The Noun Phrases give details about the referent which is 'Dangote Cement.' These are sentence fragments which are catchy phrases in advertisement that capture the attention of the audience.

In the advertisement of Dangote Cement the word 'cement' is not found in the utterances but deducible from the bags of cement and only found on the advertisement at the bottom left of the billboard. On the bags of cement on the advertisement is written, Dangote $3 \mathrm{X}$. The bold and catchy utterances are first visible so, the audience read the utterances first and get the intention of the advertiser. Ellipsis is created to attract the attention of the target audience. It entails syntactic reduction, a form of inexplicitness consisting in the unspoken, the unexpressed but understood. The omission of cement at the surface text is recoverable in relation with the rest of the text. The target audience will be able to fill the gap of omission because they have shared knowledge and shared context with the producer. According to Halliday and Hasan (1989:142) there is always a great deal more evidence available to the reader or hearer for interpreting of a sentence than is contained in the sentence itself, that is, where there is some presupposition in the structure, of what is to be supplied.

\subsection{Implying and Assuming}

Implying is about implicature, a pragmatic principle which accounts for what a speaker can imply, suggest or mean, as distinct from what the speaker literally says. This insinuates that speakers generally go beyond what they actually say. Assuming comes with presuppositions which is what the speaker considers to be the common ground of the participants in a conversation. Yule (1995, pp.100) argue that in a more general way, speakers continually design their linguistic messages on the basis of assumptions about what their hearers already know, that is, what a speaker assumes is true or is known by the hearer can be described as a presupposition making the expression and recognition of intentions an essential feature of communication. This means that the producer provides evidence of their intention to convey a certain meaning, which is inferred by the receiver on the basis of the evidence provided. According to Wilson and Sperber (1986) the central claim, the expectations of relevance raised by an utterance are precise enough, and predictable enough, to guide the hearer towards the speaker's intended meaning. Therefore in producing an utterance, the writer or speaker has to make the input relevant to readers by connecting it to available background information. It is a matter of getting the audience to recognize that one has this intention. The advertisers get the audience to recognize their intentions by involving them in a stimulus, designed to attract their attention and focus on the meaning they want to pass across.

In the Dangote Cement advertisement, the use of 'Dangote' presupposes, the reader knows the person as a prominent bourgeois and the richest man in Africa. As a dealer in cement therefore, it implies the truth of having good quality cement. The use of the triad 'strong, life, yield' presupposes the target audience know the functions and strength of cement in general, and will therefore make meaning of the fact that the cement is 'xtra Strong, xtra Life, xtra Yield.' The pre-modifier 'xtra' means an additional or exceptional quality. The implicature here is for the audience to believe in an extra strength of Dangote Cement.

The imperative is another grammatical structure used in the text which has implied meaning. It shows the relationship between the advertisers and the reader. In an imperative the grammatical mood conveys the speaker's attitude about the state of being of what the sentence describes. The imperative sentence lacks a subject and begins with a present tense verb and the second person 'you' for the subject is implied. A sentence in the imperative mood expresses commands or requests and indicates that the speaker desires for the action expressed in the sentence to take place. Imperatives have the nature of indicating power or authority, compelling the listener to carry out an action. As Chilton in Culpeper et al. 
(2009, pp.171) explains, texts are understood with their context. This is in order to understand how linguistic elements that make up texts interact with discourse and with processes in the mind to give meaning to the text.

In all that is highlighted especially there is no mention of the word 'cement.'-Get MORE, pay less , DANGOTE, 3X. The subject is deduced from the mention of 'cement' on the left side, bottom of the billboard. The effectiveness of this is to capture the interest of the readers. The audience is first introduced to the catchy statement and positive attributes before being exposed to the object of description. Before getting to the product itself, the reader's interest has been captured by the positive attributes which are, 3X (xtra Strong, xtra Life, xtra Yield). The advertisers delay the subject by first giving the qualities and cheapness of the cement. The imperative 'Get MORE' and 'pay Less' presupposes that the target audience already know the price of a $50 \mathrm{~kg}$ bag of cement, thereby implying cheapness. 'Get MORE, pay less' is a mild command in which the advertiser is giving an order even though in the sense that the consumer can reject it.

'Build with peace of mind' is another imperative that assures the reader of security in the use of the cement even though it comes as an instruction to the reader. There is a relationship here between someone who knows and is very sure of themselves and the one who is not informed. The advertiser is sure that Dangote Cement is, cheaper and very aware of the fact that building is stressful because there may be another cement which is not of good quality-it does not yield, it does not stay long and it is not strong. With this, consumers are worried, but with Dangote Cement, there is no stress. That is why the advertiser advises those building to use Dangote Cement and 'Build with peace of mind.' Commanding comes with the fact that the advertisers believe they have the power because they have the knowledge of what the consumer does not know. Their knowledge of certainty and assurance give them the power to command. The use of the two sentence fragments, 'superior quality' and 'best value for money' is like telling the reader these facts cannot be disputed. They are talking with projected authority and giving orders which are an urgent feeling to the consumer, a command that acts as an invitation. The imperatives act as instructions, advice and invitation to the readers to do something, that is, buy the cement. Pragmatically they are indirect orders used in the images of cheapness, strength and security.

\section{Building Relations}

Language is used to interact with other people, to establish and maintain relationships with them, to influence their behaviour, to express their viewpoints on things in the world and to elicit or change theirs. The focus here is on the grammatical patterns and lexical items used in texts, on the development of grammatical systems as a means for people to interact with each other, exchanging social relationships. This shows the power relations that exist between the advertiser and the consumer, though the social struggle here is less intense because the consumer is not obliged to adhere to the persuasion of the producer. Fairclough (2001, pp. 167-168) explains how advertisements work ideologically through building the market which include, building relations, building images and building the consumer. According to Fairclough's building relations, advertising discourse embodies an ideological representation of the relationship between the producer/advertiser of the product being advertised and the audience. This relationship can be viewed through the mood presented by the advertiser on the advertisement. This gives the advertiser an edge over the consumer, especially when the advertiser makes use of the power in language. In designing the advertisement the advertisers use the language resources available and work on the shared knowledge with the consumers by bringing together the text internal and text external factors to give the text a meaning. This implies that the interpreters of the advertisement bring together what they know about the world in general and the linguistic elements in the text.

The advertisers use ideology in their adverts to construct these social illusions, or to simply promote a different vision of the world and the relationships that surround both the producers and consumers. Ideologically, cheapness, quality (strength) and assurance are implied in the Dangote Cement advertisement. For the advertisers of Dangote Cement to capture the target audience, they produce an 'ostensive stimulus' (Wilson and Sperber,1986), that attracts the audience's attention, to prompt the retrieval of certain contextual assumptions and focus on the advertisers' intended meaning. The audience is able to infer into the advertiser's intention because they both have a common ground that the other brands of cement are expensive and the price of Dangote Cement will be less expensive. The imperatives function as an interpersonal relationship between the advertisers and the consumers, capturing the attention of the target audience in context of overloading information. The use of 'Build with peace of mind' in the Dangote Cement advertisement, presupposes both advertiser and target audience are conversant with the strenuous and stressful task of building. The advertisers therefore use the common ground to capture the attention of the audience because both of them can identify with the advertisements. With this the audience can infer into the intention of cheapness, quality and strength of the Dangote Cement.

\section{Conclusion}

This study has examined the use of language of advertisement as interactive, involving the producer and consumer, playing the role of the writer and the reader, considering this type of language use as situationally distinct. The study has emphasized the structural analysis and the role of context to reveal functions and underlying meanings of the text. The analysis examined Dangote Cement advertisement and shows that descriptive information about the product and that catchy phrases come before the name of the product to draw the attention of readers. Also the advertisers use different stylistic devices that carry positivity, and a common ground that makes the readers identify with the advertisers, urging them go for the Dangote Cement. 


\section{References}

Adams,Y., Matu.P., \& Oketch, O. (2014). Multimodality in Safaricon Advertisement Communication in the Kenyan Daily Nation Newspaper. Academic Journal of Interdisciplinary Studies, 3(6), pp. 403-410. Doi:10.5901/ajis.2014,v3n6p403.

Carmen, R. C. \& Malcolm, C. (2013). Texts and Practices: Readings in Critical Discourse Analysis. New York: Routledge.

Clark, H. H. (1997). Using Language. Cambridge: Cambridge University Press.

Crystal, D. (2003). The Cambridge Encyclopedia of the English Language. Cambridge: Cambridge University Press.

Culpeper, J., Katamba, F. Kerswill, P., Wodak, R., \& McEnery T. (2009) English language: Description,Variation and context. New York: Palgrave Macmillan.

Duboviciene,T. \& Skorupa, P. (2014). The Analysis of Some Stylistic Features of English Advertising Slogans. Man and the Word/Foreign Language, 16(3), pp. 61-75.

Dijk, V. (1995). Aims of Critical Discourse Analysis Japanese Discourse, 1, 17-27

Fairclough, N. (1996). Language and Power. London: Longman Group UK Limited.

Fairclough, N. (2003). Analysing Discourse: Textual analysis for social research. New York: Routledge.

Ge, L. (2011). Pragmatic Functions of Presupposition in Advertising English. Asian Culture and History, 3(1), pp.155157. DOI: http:dx.doi.org/10.5539/ach.v3nlp153.

Greenbaum, S. (1997). An introduction to English Grammar. Malaysia: Longman.

Halliday, M.A.K. \& Hasan, R. (1985). Cohesion in English. London: Longman.

Jafari, S.M, \& Mahadi,T.S.T.(2014). The Language of Advertisement and its Features and Characteristics: Investigating the Issue from a Deeper View. International Journal of English and Literature, 4(6), pp.9-14.

Jeffries,L. \& McIntyre, D. (2010). Stylistics. Cambridge: Cambridge University Press.

Jeffries, L. (2015). Textual Meaning and its place in a theory of Language. Topics in Linguistics, Issue 15. DOI: 102478/toppling-2015-0006.

Jeffries, L. (2016).Textual Meaning and Literary Interpretation: The role of Stylistics. Retrieved from .vefir.hi.is/ritverhugvisindasvids/files/2016/The-role-of-stylistics.pdf.

Kalbos, S. (2014). The Analysis of some stylistic Features of English Advertising Slogans man and the word .Foreign Language, 16(3), pp. 61-75.

Li, M (2009). The Stylistic Analysis of the Magazine Advertisement---Atkins Chocolate Chip Granola Bar. Asian Social Science, 5(9), pp. 63-69.

Lingong, Z. (2006).The Linguistic Features of English Advertising. CELEA Journal (Bimonthly, 29(1), pp. 71-78.

Nawaz, S., Bilal, H. A, Kalsoom, Fayyaz, z. \& Nayyar, H. (2013). Media discourse and their implicit Ideologies. Asian Journal of Social science and humanities, 2(2), pp. 328-337.

Simpson, P. (2004). Stylistics: A resource book for students. London: Routledge

Stanford Encyclopedia of Philosophy Plato. (2014).Stanford. edu/entries/implicature/June 24.

Stamatelou, M. (2015) A Reflection on the use of advertisements in enabling language Learning in the EFl Classroom. Vol 17 www.elted. net/ uploads/7/3/./6/7316005/v.17-5 Stamatelou. Pdf.

Talunasbi, S. \& Kalkhajeh, S.G. (20013) Critical Discourse Analysis: Iranian Banic Advertisements, 3(I), pp. 124 145 .

Sperber, D. and Wilson, D. (1986). Relevance : Communication and Cognition. Oxford: Blackwell.

Vahid, H. \& Esmae'li, S. (2012). The Power behind Images. Journal of Linguistics, 4(4), pp. 36-51. DOI:105296/ijl.v4i4.2658

Xu, Z., \& Zhou, Y. (2013). Theory and Practice in Language Studies 3(3), pp. 492-496.

Yeibo, E. (2001). A Discourse-Stylistic Analysis of mood structures in selcected Poems of J.P Clark - Bekederemo. International Journal of Humanities and Social Science, 1(16), pp. 197-203

Yinfang, W. (2007). Analysis of Presupposition and its Function in Advertisement. Canadian Social Science, 3(4), pp. 55-60.

Yule, G. (1995). The study of Language: An introduction. CUP: Cambridge. http://civiltoday.com/civil-engineeringmaterials/cement/45-properties-of-good-cement 2015

rule-of-three.co.uk/2011/7/2what-is-the-rule-of-three-copywriting,team@languageinconflict.org,

www.languageinconflict.org/the-world-through-language.html. How people present the world through language. Linguistic Toolbox.

Forbes The World's Billionaires. www.forbe.com/profile/aliko-dangote. 